\title{
PERFIS DE RESISTIVIDADE AMT: CONTRIBUIÇÃO AO RECONHECIMENTO ESTRUTURAL DA BORDA SUDESTE DA BACIA DO PARNAÍBA
}

\author{
ÍCARO VITORELLO* \& ANTONIO L. PADILHA*
}

\begin{abstract}
AMT RESISTIVITY PROFILES: CONTRIBUTION, TO THE STRUCTURAL KNOWLEDGE OF THE SOUTHEASTERN BORDER OF THE PARNAÍBA BASIN.' Resistivity data from 105 audiomagnetotelluric soundings (AMT) are used to construct eleven interpreted geoelectric sections from Floriano to Jaicos cities, in southeast Piaui State. Based on preliminary analysis of layered earth model inversion, the depth and thickness ofresistive and conductive layers are defined and tentatively related to Uthobgical sedimentary units and the basement Notwithstanding inherent limitations, gentry dipping layers, sinclines and anticlines, are followed within depths of 500 and sometimes even 1000 meters. Other geological structures, such as faults, horst and grabens are also inferred from the soundings. However, steeply dipping conductive structures and lateral conductivity inhomogeneities seem to affect horizontal layer model interpretation and require further studies. Nevertheless, the profiles indicate a highly structured basin border. Consequently, the lateral shallowing of the sedimentary layer towards the present day border might be apparent In fact, it could have been associated whh a tectonism that produced foldings and faultings. Geoelectrical evidences of major vertical displacements are seen near the cities of Floriano, Nazaré, Oeiras and Picos.
\end{abstract}

Keywords: Audiomagnetotelluric Soundings, Pamaiba Basin, geoelectric profiles, geophysical methods, geophysical reconnaissance.

\begin{abstract}
RESUMO Dados de resistividade de 105 sondagens audiomagnetotelúricas (AMT) são utilizados para compor onze perfis geoelétricos entre as cidades de Floriano e Jaicos, no sudeste do Piaui. Com base em uma análise preliminar de inversões unidimensionais e na comparacão das camadas elétricas com dados de um furo estratigrifico e com dados geológicos, a profundidade e a espessura de camadas resisti vás e conduti vás são definidas e tentativamente relacionadas a unidades Utológicas sedimentares e ao embasamento. Apesar das limitações inerentes ao método, camadas com leve mergulho, sinclinais e anüclinais, são observadas e seguidas a profundidades de 500 e muitas vezes até $1.000 \mathrm{~m}$. Outras estruturas geológicas, como falhas, horst e grábens, são também inferidas a partir das sondagens. Apesar de estruturas condutores subverticais e heterogeneidades laterais de condutividade parecerem afetar as interpretações baseadas em modelos de camadas horizontais, os perfis indicam uma borda de bacia altamente estruturada. Conseqüentemente, o afinamento lateral do pacote sedimentar em direção à presente borda pode ser aparente, estando na realidade associado a atividades tectônicas que resultariam em dobramentos e falhamentos. Evidências geoelétricas que sugerem importante movimentação vertical são observadas nas proximidades das cidades de Floriano, Nazaré, Oeiras e Picos.
\end{abstract}

Palavras-chave: Sondagens audiomagnetotelúricas, Bacia do Parnaiba, perfis geoelétricos, métodos geofisicos, reconhecimento geofisico.

INTRODUÇÃO Uma maior utilização do métọdo audiomagnetotelúrico (AMT) em investigações geológicas rasas, de algumas centenas de metros de profundidade, torna-se possivel e interessante em nível de reconhecimento geológico de bacias sedimentares. Levantamentos utilizando esse método oferecem a possibilidade de indicação da poșição (mergulho, profundidade, espessura) de camadas resistivas e condutivas, freqüentemente associadas às camadas sedimentares e estruturas geoló gicas. Ressalte-se que uma campanha AMT é facilmente realizada, com grande economia de recursos e resultados altamente satisfatórios, como atestam os trabalhos de Hoover et al. (1976), Strangway \& Koziar (1979), Ádám et al (1982), Lakanen (1986) e Padilhaefo/. (1989).

O método, entretanto, apresenta diversas limitações. 0 seu poder de resolucão é relativamente baixo e decresce ainda mais com a profundidade, tendo acentuada dependência com altos contrastes de condutividade entre camadas sobrepostas. Como conseqüência, a incerteza nas determinações das profundidades aproxima-se de $15 \%$, na melhor das hipóteses (Billings \& Thomas 1990). Também, por ser altamente sensível às variacões laterais das propriedades elétricas das camadas e à interferências no sinal eletromagnético natural, pode-se ter problemas com a discordância entre leituras repetidas em um mesmo local (Padilha \& Vitorello
1993). Maiores detalhes sobre a utilização genérica dos métodos magnetotelúricos podem ser obtidos no artigo de revisão de Vozoff (1990).

Neste trabalho, apresenta-se uma discussão sobre as potencialidades e limitações das sondagens AMT, tendo em vista sua contribuiç̃a ao conhecimento estrutural e litoestratigráfico da margem sudeste da Bacia do Parnaiba, no Estado do Piauí.

\section{CARACTERÍSTICAS GERAIS DA ÁREA DE} ESTUDO Geologia, geofísica e relevo $O$ esboço geológico da sequência paleozóica que ocorre na área em estudo (Fig. 1) é apresentado na figura 2 e uma seção esquemática é exibida na figura 3 , adotando-se a coluna litoestratigrá fica utilizada por Cunha (1986).

A secão esquemática da figura 3 baseia-se nos dados estratigráficos do furo 1-FL-1-PI da Petrobrás (representado por Fl1 nas figuras), a NW da área, e a sua extrapolação para SE, em direção à borda (Fig. 2), condiciona-se as informações dos mapas geológicos de Lima \& Leite (1978) e Cunha (1979). No sudeste do Piaú, a leste do Rip Parnaiba, as camadas sedimentares afloram em faixas semicirculares com direcão norte e sudoeste, e mergulham suavemente para oeste. De acordo com Cunha (1 986), as Formações Ipú, Tianguá e Jaicos pertencem ao Grupo Serra Grande e as Formações 


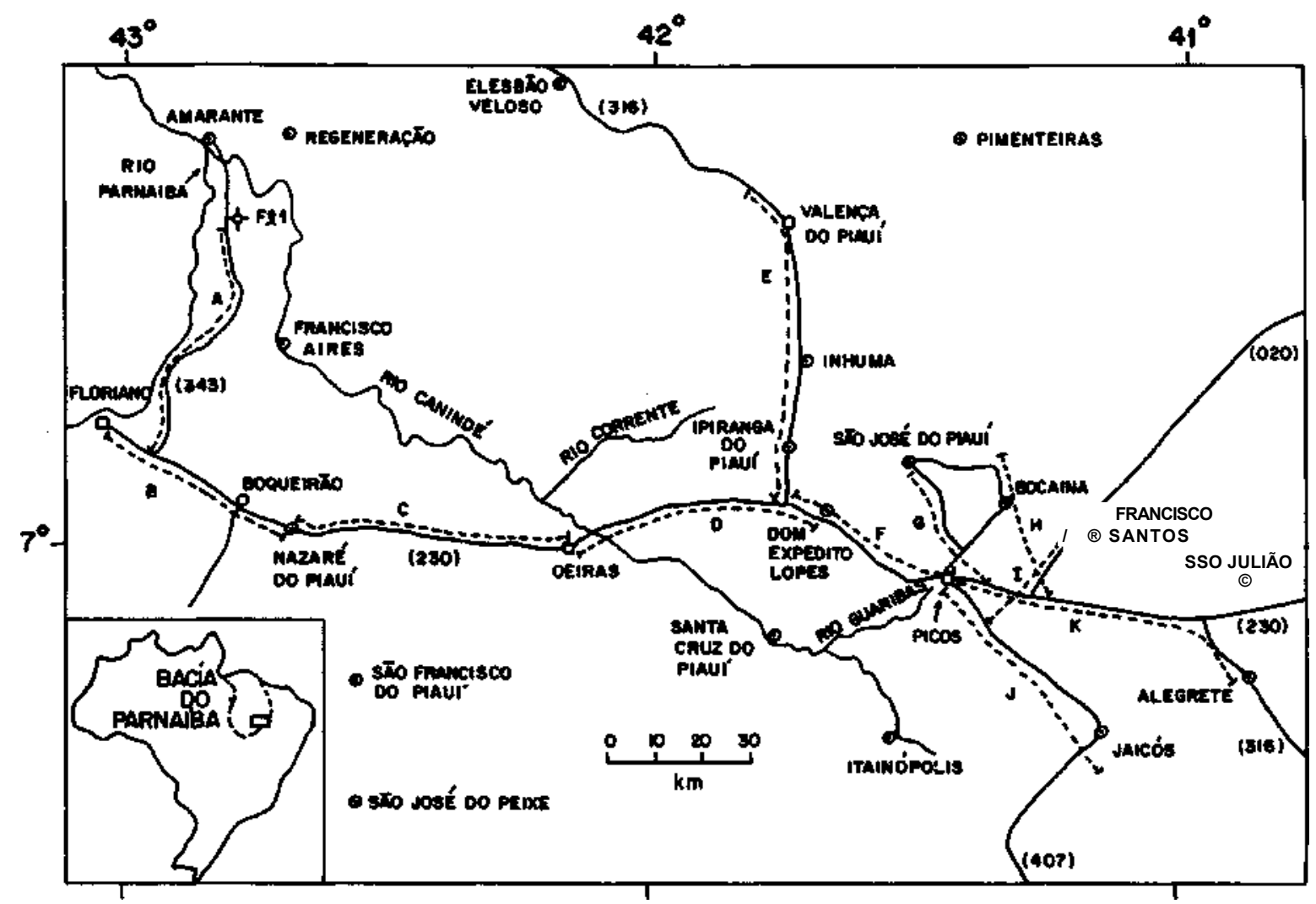

Figura 1 -Mapa da área de trabalho, mostrando a localização dos onze perfis geoelétricos levantados (linhas tracejadas) ao longo das rodovias (linhas contínuas, numeração da estrada entre parênteses), no sudeste do Estado do Piauí Figure l - Location map of the study site, showing the eleven geoelectric profiles (dashed lines), along roads (full lines, road number within parentheses), in southeast Piauí State

Itaim, Pimenteiras, Cabeças e Longa formam o Grupo Canindé. A coluna paleozóica encerra-se pela Seqüência Poti, Pedra de Fogo e Motuca, sendo que essa última formação não aflora na área deste estudo (Fig. 2). Como a carta geológica consultada para a porção leste da área (Lima \& Leite 1978) apresenta a faixa de sedimentos arenosos a leste da Formação Pimenteiras como pertencente à Formação Serra Grande, na qual a Unidade Itaim é considerada um de seus membros, vai-se utilizar a expressão "arenitos não-diferenciados", quando não for possível distinguir a Formação Itaim (Grupo Canindé) do Grupo Serra Grande.

O pacote sedimentar na área de estudo é constituído, portanto, pela alternância de camadas predominantemente arenosas (Formações Ipú, Jaicós, Itaim e Cabeças), essencialmente pelíticas (Tianguá, Pimenteiras e Longa) e por uma seqüência rítmica de níveis arenosos, siltitos arenosos, arenitos argilosos e camadas mais argilosas (Poti e Piauí). Além das unidades apresentadas no corte geológico da figura 3, duas outras unidades são encontradas na área (Fig. 2): Pedra de Fogo e Pastos Bons. A Formação Pedra de Fogo, unidade paleozóica constituída por siliciclásticos finos, repousa em concordância sobre a Formação Piauí, e é encontrada na porção NW. A Formação Pastos Bons, constituída por sedimentos finos do Mesozóico, assenta-se com discordância sobre unidades paleozóicas, onde preenche um paleorrelevo geralmente ondulado, e é encontrada na parte central da área em estudo. Rochas intrusivas básicas também estão presentes em vários pontos, na forma de diques e soleiras. A possibilidade de ocorrência de sedimentos présilurianos soterrados em grábens sob os sedimentos paleozóicos não é remota, devido à presença de feições com forma de gráben preenchidas por sedimentos imaturos ao lado da borda leste da bacia, especificamente na região de Cococi e de São Julião.
O embasamento da bacia na área deste estudo é dominado por metassedimentos dobrados e rochas metamórficas (Lima \& Leite 1978).

Em termos estruturais, a área situa-se a leste do Lineamento Transbrasiliano, a oeste do prolongamento para sul do Lineamento Senador Pompeu, ambos de direção NE-W, ao sul do Lineamento Picos-Santa Inês e a norte do prolongamento para leste do Lineamento Pernambuco, esses dois ủltimos com direção NW-SE. Detalhes sobre esses lineamentos são encontrados em Cordani et al. (1984) e Cunha (1986).

As informações geofísicas da área, por outro lado, são extremamente escassas, como pode ser observado no trabalho de Góes et al (1990). Dados gravimétricos, restritos à região ao norte do paralelo $6^{\circ} \mathrm{S}$, foram analisados por Beltrão et al (1991). Os autores demonstram, entre outras informações, o realce da posição geográfica de diversas falhas, sendo as mais conspícuas aquelas associadas ao Lineamento Transbrasiliano. Para este trabalho, no entanto, os dados mais oportunos são aqueles dos levantamentos de eletro-resistividade e de foros hidrogeológicos, realizados pela Sudene nas décadas de 60 e 70, nas regiões de Floriano-Oeiras e Picos.

Quanto ao relevo, a área é caracterizada por feições elevadas, porém planas, formando extensas chapadas, muitas vezes limitadas por escarpas. Essas chapadas são constituídas por unidades predominantemente arenosas ou são sustentadas por níveis de alta resistência à erosão, como os silexitos. Nessas áreas, o nível freático é profundo, alcançando centenas de metros.

Nas áreas rebaixadas, onde predominam os sedimentos impermeáveis das unidades pelíticas, a rede de drenagem é bem desenvolvida e o nível freático encontra-se próximo à superfície. Entretanto, intercalações arenosas em unidades pelíticas formam pequenas elevações abauladas espaçadas sobre as planícies. 


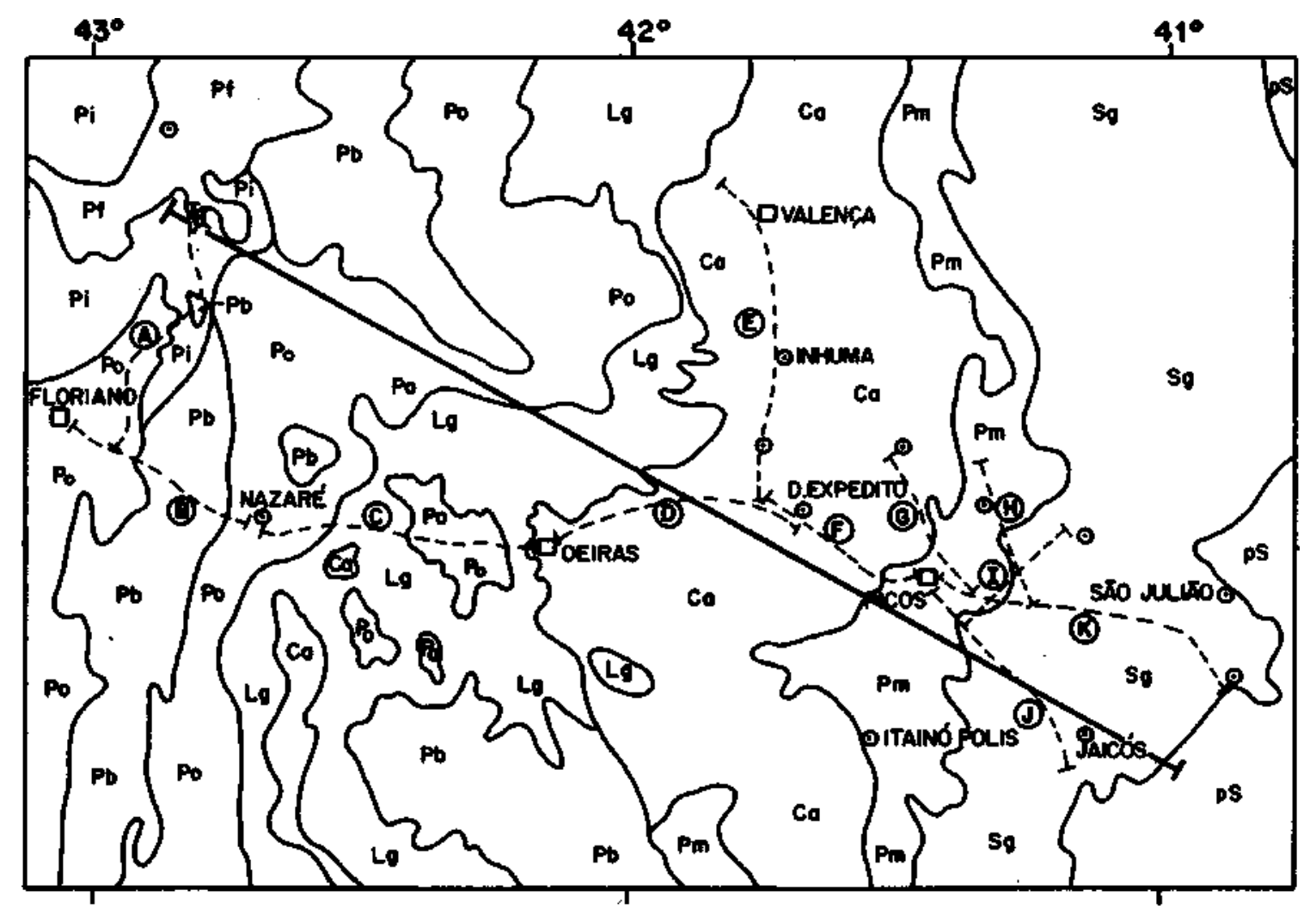

Figura 2 - Mapa simplificado da geologia da região de trabalho, mostrando a localização das principais faixas de afloramentos das camadas sedimentares. Os símbolos representam as seguintes unidades: $\mathrm{Pb}=$ Pastos Bons; Pf= Pedra de Fogo; $\mathrm{P} i=$ Piauí; Pó = Poti; Lg - Longa; Ca = Cabeças; Pm = Pimenteiras; Sg = Grupo Serra Grande (Adaptado de Lima \& Leite (1978) e Cunha (1979))

Figure 2 - Simplified geologic map of the study site showing the main outcropping sedimentary strata. The symbols stand for the following units: $\mathrm{Pb}=\mathrm{Pastos} \mathrm{Bons}$; Pf = Pedra de Fogo; Pi = Piauí; Pó = Poti; Lg = Longa; Ca = Cabeças; Pm = Pimenteiras; Sg = Grupo Serra Grande (Adapted from Lima \& Leite (1978) and Cunha (1979))

A principal rede de drenagem da área é constituída pelo Rio Canindé e seus afluentes, os quais atravessam transversalmente as unidades geológicas, seguindo a direção SE-NW. $\mathrm{O}$ curso do rio, entre Itainópolis e Francisco Aires (Fig. 1), é bastante retilíneo, o que sugere um encaixe estrutural (Nunes et al 1973).

Aspectos climáticos $\mathrm{O}$ planejamento das sondagens AMT requer o levantamento de informações climáticas por duas razões: a interferência das tempestades elétricas no sinal e o efeito do teor de água na resistividade das camadas sedimentares porosas.

$\mathrm{Na}$ área em estudo, o clima é marcado pelas condições semi-áridas do nordeste: insuficiência generalizada e má distribuição espacial e temporal de chuvas, temperaturas elevadas e acentuada evaporação. Em termos de variação geográfica, observa-se uma forte diminuição de precipitação no sentido de NW para SE: em Amarante, a precipitação média anual é de aproximadamente $1.400 \mathrm{~mm}$, em Floriano é de $900 \mathrm{~mm}$, em Oeiras $830 \mathrm{~mm}$ e em Picos $550 \mathrm{~mm}$.

No período de chuvas, que ocorrem entre novembro e abril, contendo $90 \%$ do total da precipitação anual, destacam-se os meses de janeiro a março (55\% do total). Para a época de estiagem, entre maio e outubro, destaca-se o período de junho a setembro, quando as precipitações não somam $2 \%$ do total anual.

Este estudo foi realizado na segunda quinzena do mês de abril de 1991, no final da estação chuvosa. Com essa programação espera-se ter minimizado a presença de tempestades locais, o que foi confirmado através de consulta ao
Climanálise (1991). Essa publicação forneceu informações sobre atividades convectivas e sistemas frontais que passaram pela região na época das medidas; essas informações foram confrontadas com os dados de sondagem para detectar possíveis interferências nos sinais.

Outro aspecto relevante é que o final da estação chuvosa corresponde a condições de plena recarga dos aqüíferos e de máximo patamar para o lençol freático. Essas condições devem produzir um aumento generalizado da condutividade, diminuindo conseqüentemente os problemas de interferência no sinal, apesar de realçarem possíveis heterogeneidades laterais. Devido ao importante papel desempenhado pelo teor de água na condutividade das camadas, Padilha et al. (1992) recomendam a realização de duas campanhas de sondagens, respectivamente no final do período chuvoso e de estiagem. Nesse último caso, as condições de maior resistividade favorecem uma maior penetração do sinal, mas ao mesmo tempo realçam as interferências e a sensibilidade a variações laterais.

De acordo com os dados da Climanálise, no período de janeiro a abril de 1991, antecedente ao período de sondagem, as condições de precipitação foram normais na região NW de Oeiras, porém deficiente em relação à média do período na região a SE daquela cidade. No entanto, ainda segundo os dados da Climanálise (1992), o ano de 1990 foi considerado mais seco que o normal, para toda a região nordeste do país.

SONDAGENS AUDIOMAGNETOTELÚRICAS E INVERSÃO DE DADOS As sondagens AMT referem- 


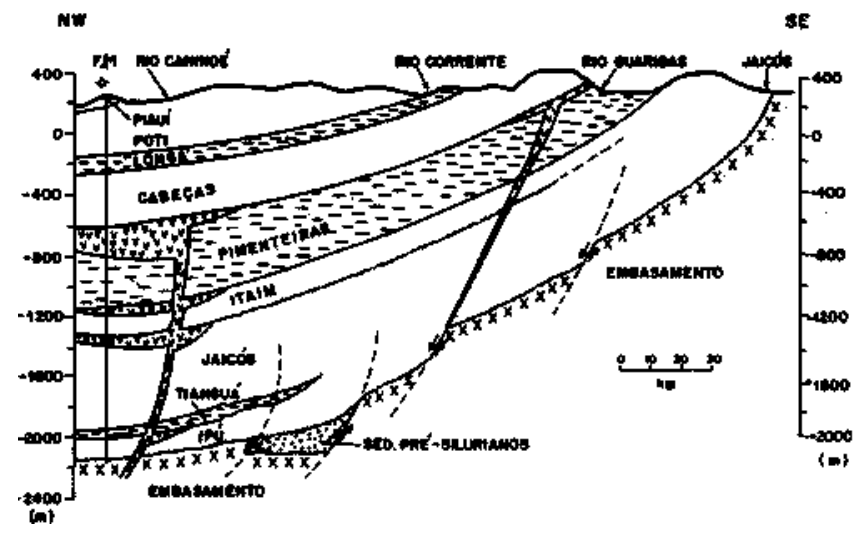

Figura 3 - Seção esquemática da geologia do sudeste da Bacia do Parnaiba, a partir do furo litoestratigráfico F1 l (PETROBRÁS1-FL-1-P1) nas proximidades do Rio Parnaiba, na direção da borda oriental a sudeste de Jaicós (PI), como indicado na figura 2. A profundidade é expressa em metros Figure 3 - Geological cross-section outline in southeastern Parnaiba Basin, from a lithostratigraphic borehole, Fl I (PETROBRÁS 1-FL-1-PI), near the Parnaíba river, in the direction of the eastern border, southeast of Jaicós (PI), as indicated in Figure 2. The depth is in meters

se a determinações magnetotelúricas das variações simultâneas dos campos naturais elétricos e magnéticos, restritos a faixa de freqüência maior que $1 \mathrm{~Hz}$. Nessa faixa de "alta freqüência", a energia eletromagnética (EM) tem origem nas tempestades elétricas, cuja distancia e direção de ocorrência é muito importante. O modelo utilizado no desenvolvimento teórico requer ondas EM planas, que atravessem verticalmente camadas horizontais homogêneas e isotrópicas, gerando o fenômeno de indução eletromagnética. Tempestades locais e ruídos culturais, tais como interferências causadas por linhas de alta tensão e motores, ocasionam determinações não confiáveis, principalmente em terrenos resistivos. Anomalias de resistividade próximas à superfície, no local de sondagem, originam o efeito de deslocamento estático (static shift), que eleva ou rebaixa toda a curva de sondagem, independentemente da freqüência.

Na prática, determina-se na superfície terrestre a relação entre os campos elétrico e magnético mutuamente perpendiculares, com um sensor magnético alinhado ortogonalmente a um dipolo elétrico sensível ao campo elétrico induzido, ambos em posição horizontal. A razão entre os dois campos é a impedância encontrada pela onda EM incidente que, por sua vez, relaciona-se à resistividade aparente da área de medidas. Em condições litológicas nas quais a condutividade só se altera verticalmente, as resistividades aparentes determinadas, variando as freqüências de observação, referem-se a um volume de material verticalmente distribuído até uma certa profundidade. As freqüências mais elevadas relacionam-se à parte superior e à medida que se diminui a freqüência, um volume maior de material, a maiores profundidades, é integrado para fornecer o valor da resistividade aparente. Conclui-se, assim, que o método é mais eficiente em condições litológicas de pouca variação lateral, sendo indicado na discriminação de camadas condutoras homogêneas com extensa expressão lateral. Em regiões com variações litológicas laterais, por outro lado, é sempre observada uma acentuada dependência na direção de origem do sinal e da heterogeneidade. A par disso, em terrenos verticalmente condutivos, a energia é atenuada em profundidades comparativamente menores que em terrenos resistivos. Por essa razão, as maiores profundidades de penetração são obtidas em áreas de coberturas mais resistivas.

A figura 4 mostra um exemplo de sondagem AMT. No lado esquerdo, observa-se a variação da resistividade aparente obtida em função da freqüência, que diminui da esquerda para a direita ao longo da abscissa, em direção a maiores profundidades.

As leituras são realizadas em freqüências discretas e a dispersão nas determinações em cada freqüência é indicada por barras verticais no gráfico da figura 4 . As duas curvas, linhas contínuas e tracejadas, representam o melhor ajuste para os dados obtidos nas freqüências indicadas, com a posição do dipolo elétrico em duas direções ortogonais.

A convergência ou divergência entre as duas curvas é, respectivamente, um indicador de condições internas homogêneas (caso unidimensional) ou heterogêneas (multidimensional). Como os terrenos geológicos raramente são lateralmente homogêneos, com exceções encontradas em bacias sedimentares, freqüentemente são observadas divergências entre as duas curvas. A presença dessa divergência é um indicador de heterogeneidades laterais na condutividade das camadas, mostrando que a direção da corrente induzida é parcialmente controlada por variações litológicas laterais. Nesses casos, a análise dos dados torna-se extremamente complexa.

Para haver uma interpretação geológica a partir das curvas de resistividade aparente em função da freqüência, é necessário que elas sejam convertidas em variações de conduti-
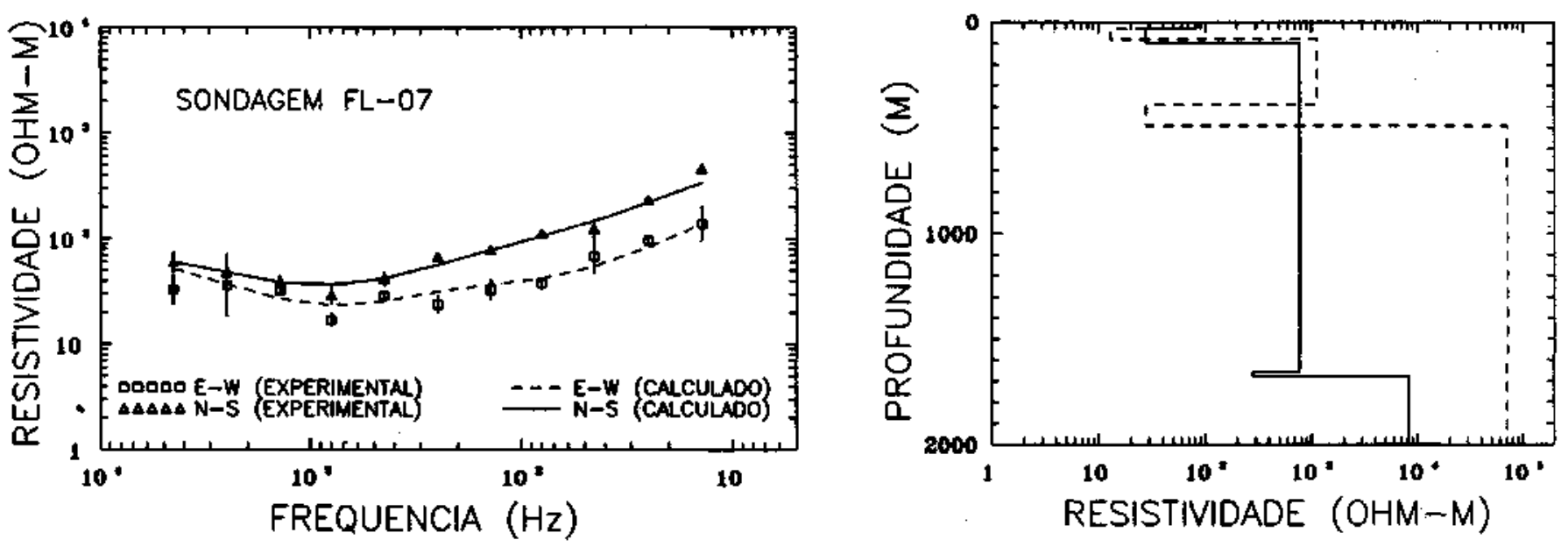

Figura 4 - Exemplo de inversão de dados AMT: o gráfico à esquerda mostra os dados da sondagem; à direita, é exibido o melhor ajuste para um modelo de camadas 1-D que explica os dados observados

Figure 4 - Example of AMT data inversion: at left, the observed data; at right, the best-fitting 1-D layered-earth model that explains the observations 
vidade (resistividade) em função da profundidade. Para tanto, são utilizados modelos numéricos de inversão. Na modelagem unidiraensional (1-D), variam-se espessuras e resistividades de cada uma das camadas, consideradas horizontais, homogêneas e isotrópicas, até se encontrar a seqüência que gere a maior consistência com os dados observados (ver, p. ex., Jupp \& Vozoff 1975). O gráfico à direita da figura 4 demonstra que, em condições de variações laterais, a inversão dos dados em cada direção fornece seqüências distintas de camadas. Na ilustração, observa-se uma concordância aproximada entre as duas inversões até cerca de $400 \mathrm{~m}$ de profundidade. Há uma seqüência que se inicia com uma camada fracamente resistiva, próxima à superfície, seguida por uma camada condutora e outra resistiva. Na direção EW, a inversão mostra uma camada condutora entre 400 e $500 \mathrm{~m}$, seguida por uma base resistiva. Por outro lado, na direção NS, essa camada não é detectada, embora uma fina camada condutora seja discriminada a $1.700 \mathrm{~m}$ de profundidade, acima da base resistiva. As implicações desses resultados serão discutidas posteriormente.

PERFIS DE RESISTIVIDADE Cento e cinco sondagens AMT foram obtidas em 14 dias de campanha, em abril de 1991, ao longo das principais rodovias do sudeste do Piauí (Fig. 1). Essas sondagens estão dispostas na forma de 11 perfis de resistividade.

As determinações de resistividade foram realizadas com um sistema portátil $(12 \mathrm{~kg})$, escalar, calibrado para fornecer, em freqüências digitalmente selecionadas entre 1 e $5.000 \mathrm{~Hz}$, a resistividade aparente e a coerência entre os sinais magnéticos e elétricos (ver Padilha et al. 1993, para detalhes). Em cada freqüência selecionada, uma série de leituras de alta coerência fornece uma média e respectivo desvio padrão, usados na construção das curvas de sondagens, como ilustrado na figura 4.

O local de sondagem é escolhido em relevos planos e distantes de interferências culturais, cuja intensidade pode ser detectada com um sensor de $60 \mathrm{~Hz}$. A distância entre pontos de sondagem variou entre algumas centenas de metros e alguns quilômetros. Em cada sondagem, duas seqüências de leituras foram realizadas com cada um dos sensores, elétrico (dipolo) e magnético (magnetômetro), em posição geométrica aproximadamente paralela e perpendicular à direção das camadas. A instalação e a conclusão de todas as leituras em cada estação são realizadas em aproximadamente $30 \mathrm{minu}-$ tos, dependendo da qualidade dos sinais. Em geral, um ou dois operadores realizam de 8 a 16 sondagens por dia, dependendo das condições atmosféricas e dificuldades de locomoção entre as estações.

Os perfis geoelétricos foram construídos a partir das camadas obtidas pelas inversões de cada sondagem, projetadas em planos para facilitar a visualização da extrapolação lateral. Nos perfis, as linhas sólidas indicam as continuidades laterais dos contatos entre as camadas, enquanto as tracejadas indicam os contatos inferidos.

INTERPRETAÇÕES PRELIMINARES Em uma bacia sedimentar, a possibilidade de discriminação de camadas condutoras e resistivas associadas a unidades litológicas depende de dois fatores: aqueles ligados às condições ideais do modelo teórico descrito anteriormente e aqueles relacionados ao contraste em condutividade entre camadas sobrepostas. As unidades litológicas definidas por camadas homogêneas espessas, separadas de outras unidades por contatos estratigráficos bem definidos e de alto contraste em condutividade, são favorecidas pelo método. Em terrenos condutivos, a resolução do método diminui muito mais rapidamente com a profundidade do que em terrenos resistivos. Esses, por outro lado, são muito mais afetados por interferências ao sinal e pela anisotropia e heterogeneidade das camadas.
Em rochas sedimentares, o processo de condução depende, em princípio, de sua constituição. No entanto, o fluxo elétrico é facilitado pela presença de íons dissolvidos na solução que preenche os interstícios dos sedimentos e a sua intercomunicação. Devido a isso, existe uma relação direta entre condutividade e porosidade, teor de sais e variação de temperatura. Conclui-se, portanto, que os processos de compactação e cimentação, que produzem a diminuição da porosidade e permeabilidade em função da profundidade, dificultariam a condutividade. Em contraste, o aumento da temperatura e salinidade dos fluidos com a profundidade facilitariam a condutividade.

Dessa forma, as condições que propiciam um aumento de condutividade em bacias sedimentares são: teor de argila, concentração de sais nos fluidos intersticiais, porosidade e seu preenchimento por fluidos salinizados. Portanto, as camadas litológicas que geralmente se apresentam como condutoras são as unidades pelíticas, onde predominam os folhelhos, principalmente aqueles ricos em matéria orgânica, e os sedimentos siliciclásticos com alta porosidade, quando saturados por soluções salinas. A condutividade também é realçada em zonas de fraturas, carst, diques e seleiras fraturadas e preenchidas por fluidos. Por outro lado, rochas nãointemperizadas ou não-fraturadas, como arenitos não saturados, calcários, dolomites, rochas metamórficas e ígneas são predominantemente resistivas.

Resultados De maneira geral, as sondagens revelam que a Bacia do Parnaíba, na sua porção sudeste, aproximase das condições unidimensionais ideais exigidas pelo modelo teórico. Também, o nível do sinal EM é relativamente forte, provavelmente devido à proximidade das tempestades equatoriais. Entretanto, as interferências no sinal ocorrem com freqüência pelo fato da superfície ser bastante resistiva, principalmente nas chapadas arenosas. Como esperado, as sondagens mostram que, entre as unidades aflorantes, as resistividades mais elevadas e condições de anisotropia mais acentuadas são encontradas nessas chapadas, ao contrário do que ocorre nas planícies, onde predominam as unidades pelíticas.

Quanto aos efeitos de deslocamento estático, existem duas maneiras de corrigi-los: levantamentos de resistividade elétrica conduzidos por métodos distintos dos magnetotelúricos, como o método transiente e o de eletro-resistividade, ou normalizando todas as sondagens realizadas em uma área litologicamente homogênea pela média dessas sondagens. Destaque-se que essa última abordagem requer o reconhecimento prévio dos limites de cada área litológica. Nesta etapa do trabalho, esses efeitos não foram corrigidos, tendo sido utilizadas apenas as inversões l-D sobre dados aparentemente não afetados por quaisquer interferências. Na elaboração dos modelos iniciais para as inversões 1-D, foram utilizadas informações geológicas e geofísicas disponíveis. A possibilidade de efeitos de deslocamento estático também foi levada em consideração por ocasião das interpretações preliminares. De modo geral, porém, a concordância com os dados de eletro-resistividade de Cruz \& Peixoto (1972) sugere que o deslocamento estático não é muito importante, ao menos na parte ocidental da área.

Devido à limitação de páginas, apresentaremos a seguir somente os perfis com as interpretações preliminares. As extrapolações dos contatos entre camadas resistivas e condutivas, indicadas no gráfico respectivamente por letras maiúsculas e minúsculas, e indicações de possíveis falhas são meras representações qualitativas que buscam facilitar a visualização regional dos dados obtidos.

PERFILA O perfil A (Fig. 5) posiciona-se aproximadamente na direção NS, ao longo da Rodovia 343, com início, ao norte, nas proximidades do furo 1-FL-1-PI, e término, ao sul, 
no cruzamento com a Rodovia 230, em direção a Floriano. $\mathrm{Na}$ extremidade norte, duas sondagens, isoladas das demais, definem uma seqüência de três camadas. A camada $\mathbf{F}$, fracamente resist $\mathrm{i}$ vá (média e desvio padrão de $174 \pm$ $10 \mathrm{ohm} . \mathrm{m})$, é interpretada como correspondendo aos siltitos e folhelhos não saturados da Formação Pedra de Fogo, que afloram na área de sondagem e na região ao norte (Fig. 2). Essa camada sobrepõe-se à camada $\mathbf{i}$, moderadamente condutora ( $24 \pm 7 \mathrm{ohm} . \mathrm{m})$, que coincide com a posição da Formação Piauí ño furo 1-FL-1-PL Abaixo dessas camadas, as sondagens registram um pacote moderadamente resistivo, cuja parte superior corresponde à Formação Poti. Nesse local, o método não consegue discriminar as outras camadas, que na figura 5 são indicadas por linhas tracejadas a partir das informações do furo 1-FL-1-PL As letras I, C, p e D

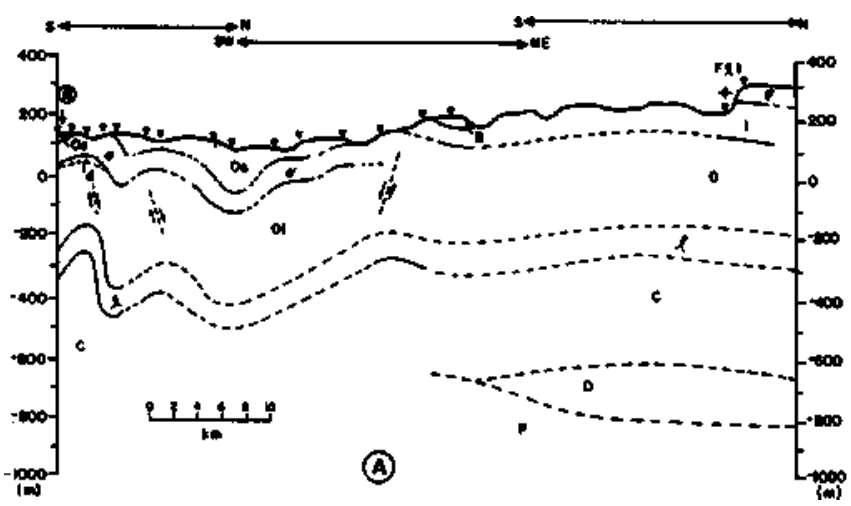

Figura 5 - Interpretação preliminar do perfil geoelétrico A, direção norte-sul, ao longo da rodovia 343 até o entroncamento com a Rodovia 230, ao sul. Triângulos invertidos indicam a posição das sondagens * Figure 5 - Preliminary interpretation of geoelectric profile A, north-south direction along road 343 up to the Road 230, to the south. Sounding positions are indicated by inverted triangles

correspondem, respectivamente, às Formações Longa, Cabeças e Pimenteiras e ao diabásio.

Mais ao sul, as sondagens definem uma camada superficial B, fracamente resistiva (53 $\pm 24 \mathrm{ohm} . \mathrm{m})$, sobreposta a uma camada condutora $(10 \pm 4 \mathrm{ohm} \mathrm{m})$ e outra mais resistiva. Esse conjunto é interpretado como sendo Pastos Bons, Piauí e Poti, respectivamente. Uma transição para um pacote resistivo a maiores profundidades é interpretado como sendo a base da Longa.

Em direção SW, ao se aproximarem do Rio Parnaíba, as sondagens mostram um comportamento distinto do anterior. Saliente-se que, aproximadamente nessa região, o mapa do projeto RADAM (Nunes et al 1973) indica a ocorrência de uma falha com direção NW-SE. A interpretação dos dados AMT indica, na parte superior, uma camada Os moderadamente resistiva $(206 \pm 230 \mathrm{ohm} . \mathrm{m})$, que se aprofunda e torna-se mais resistiva em direção ao rio. Essa camada é seguida por uma camada condutora o (21 18 ohm.m) sobre um pacote resistivo Oi. À medida que as sondagens se afastam do rio, em direção ao sul, a camada superior Os se afina e a camada o aproxima-se da superfície e chega a aflorar. $\mathrm{Na}$ parte meridional do perfil, a alternância de camadas condutora (o), resistiva (Oi), condutora (I) e resistiva (C) é interpretada como correspondendo aos membros pelíticos e arenosos do Poti, ao Longa e Cabeças, respectivamente. Uma fina camada moderadamente condutora $\mathbf{d}$, sob a camada o, pode ter correspondência com as intrusivas básicas que afloram na região.

Esses resultados são concordantes com os dados de eletro- resistividade e de furos de água, publicados em Feitosa (1970) e Cruz \& Peixoto (1972).

PERFIL B O perfil B (Fig. 6) estende-se de Floriano a Nazaré (Rod. 230), em direção SE, aproximadamente em concordância com a direção de mergulho regional das camadas sedimentares. Em sua porção oeste, os resultados mostram o mergulho das camadas Os, o e Oi em direção ao Rio Parnaíba, em consonância com a parte do perfil A que se aproxima do mesmo rio. A camada I, condutora (31 \pm $10 \mathrm{ohm} . \mathrm{m})$, apresenta-se com acentuada dobra, em situação similar à parte meridional do perfil A. Outras interpretações plausíveis, em substituição à dobra, seriam a presença de falha normal, com direção SW-NE e mergulho N W, ou a ocorrência de uma combinação de dobra e falha. O mapa do projeto RADAM (Nunes et al. 1973) apresenta uma falha inferida com essa orientação.

A figura 4 ilustra a sondagem Fl-07 obtida no ponto de intersecção dos perfis A e B, exemplificando o comportamento de diversas sondagens dessa área. Nessas sondagens, a direção de dipolo $\mathrm{EW}$, coincidente com o mergulho das camadas, realça a camada condutora 1 , a $400 \mathrm{~m}$ de profundidade, com forte mergulho para NW e dobra com mergulho suave para SE. Supondo uma correspondência da camada I com a Formação Longa, as unidades sedimentares estariam aparentemente rebaixadas em pelo menos $300 \mathrm{~m}$, em relação ao furo 1-FL-1-PI na parte oeste do perfil B.

Em algumas sondagens, detectou-se uma base resistiva (resistividades superiores a $10 \mathrm{ohm} . \mathrm{m}$ ) que poderia relacionar-se ao embasamento cristalino (Fig. 4). A partir dessas sondagens, pode-se estimar rebaixamentos abruptos no embasamento, com pelo menos 460 m, em direção NW. Dados

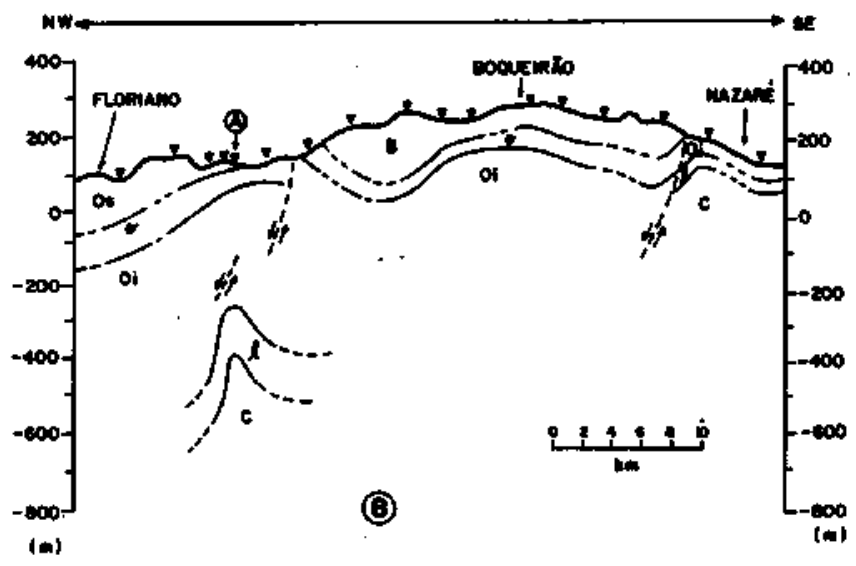

Figura 6 - Perfil geoelétrico B, de Floriano até Nazaré do Piauí, ao longo da Rodovia 230. O ponto de cruzamento com o perfil A é indicado pela letra A em um círculo

Figure 6 - Geoelectrical profile B, from Floriano until Nazaré do Piauí, along Road 230. The point where profile B intersects profile A is indicated by the encircled letter A

de duas sondagens chegam a indicar cotas de $-1.470 \mathrm{~m} \mathrm{e}$ $1.930 \mathrm{~m}$. Aceitando uma imprecisão de $15 \%$, esses resultados corresponderiam a um degrau de $530 \mathrm{~m}$, ou seja, um rebaixamento de uma cota de $-1.690 \mathrm{~m}$ para $-2.220 \mathrm{~m}$, esta última em razoável concordância com o poço 1-FL-1-PI (Fig. 3). Assim, se a parte superior dos sedimentos apresenta $300 \mathrm{~m}$ de rebaixamento na parte oeste, pode-se concluir que a porção inferior dos sedimentos dessa mesma área seriam menos espessos devido à profundidade do embasamento. Uma outra interpretação possível seria que a base resistiva indicada pela sondagem corresponderia à base da Formação Tianguá, 
e o embasamento estaria a uma profundidade bem maior do que o encontrado em 1-FL-1-PI, ou mais precisamente a uma cota de $-2.500 \mathrm{~m}$.

Na parte central do perfil, região de Boqueirão, a camada B, com resistividade alta porém bastante variável (1.460 \pm $1.840 \mathrm{ohm} . \mathrm{m})$, apresenta uma feição longitudinal ondulada. Essa camada pode representar a Formação Pastos Bons, que aflora em toda a região. Segue-se a ela uma camada condutora o $(11 \pm 13$ ohm.m) sobre uma base resistiva Oi. Com essa interpretação, a camada resistiva Os, observada na porção NW do perfil, não estaria representada sob a Formação Pastos Bons e, conseqüentemente, os dobramentos envolveriam também as unidades mesozóicas. O mais provável, porém, é que a unidade litológica correspondente à camada $\mathbf{O s , ~ p o r ~}$ ser resistiva, estaria inclusa na camada $\mathbf{B}$, não sendo assim discriminada. Dessa forma, os dobramentos observados permaneceriam restritos aos sedimentos paleozóicos. Quanto à Formação Longa, em Boqueirão, seu topo estaria ao redor da cota $-250 \mathrm{~m}$.

Na região de Nazaré, a camada resistiva Oi superior $(990$ $\pm 1.100 \mathrm{ohm} . \mathrm{m})$ representaria o nível inferior, não saturado, da Formação Poti, que aflora nos arredores de Nazaré. De acordo com essa interpretação, o topo dos níveis pelíticos da Formação Longa estaria nas cotas entre 100 e 150 m, enquanto os arenitos da Formação Cabeças estariam a menos de $100 \mathrm{~m}$ da superfície, o que é confirmado por furos de água. A veracidade desses resultados implica em um soerguimento de $300 \mathrm{~m}$ do bloco onde a cidade de Nazaré encontra-se localizada, com basculamento de NW para SE.

De acordo com os dados de eletro-resistividade de Cruz \& Peixoto (1972), a profundidade do topo da Formação Cabeças estaria situada em uma cota de $-470 \mathrm{~m}$ a $15 \mathrm{~km}$ SE de Floriano, subiria para $-220 \mathrm{~m}$ em Boqueirão e para $30 \mathrm{~m} \mathrm{em}$ Nazaré. Esses resultados estão de acordo com a interpretação dos dados AMT apresentada na figura 6.

PERFIL C O perfil C (Fig. 7) é uma continuação para leste, na Rodovia 230, do perfil anterior, cobrindo o trecho entre Nazaré e Oeiras. Na sua pane ocidental, as camadas apresentam a mesma seqüência encontrada em Nazaré, até a região onde se iniciam afloramentos de diabásio (d). Interpreta-se aqui uma faixa contendo uma feição com forma de gráben, a leste da qual as camadas estão soerguidas de 150 a $200 \mathrm{~m}$. Nessa região, as sondagens começam a registrar uma camada condutora $\mathrm{p}$, na cota de $-400 \mathrm{~m}$, sobre uma base resistiva I. Essa seqüência é interpretada como sendo unidades pelíticas da Formação Pimenteiras sobre os arenitos da Formação Itaim. As camadas apresentam-se levemente onduladas e formam um amplo anticlinal, na parte central do perfil, e um sinclinal, próximo a Oeiras. Essas feicões estão também registradas no levantamento geológico de Cruz \& Peixoto (1972).

A oeste de Oeiras, a Formação Cabeças aflora e o topo da camada $p$ alcança o nível do mar, o que requer um soerguimento de aproximadamente $250 \mathrm{~m}$.

PERFIL D O perfil D (Fig. 8) segue em direção NE por $30 \mathrm{~km}$ e para SE no trajeto seguinte da Rodovia 230. A Formação Cabeças aflora em toda a extensão do perfil. Os dados das sondagens indicam uma seqüência de camadas resistiva-condutiva-resistiva, designadas respectivamente por $\mathrm{C}, \mathrm{p}$ e I, e algumas camadas delgadas d, na parte superficial. A camada p ilustra o caráter ondulado dessa seqüência e um soerguimento de aproximadamente $400 \mathrm{~m}$. Na parte oriental do perfil, o topo de p encontra-se a $300 \mathrm{~m}$, enquanto em sua extremidade ocidental essa mesma camada situa-se na cota de -100 m. A região de Dom Expedito, em particular, aparenta ser um alto estrutural. A possibilidade de falha normal é indicada para o ponto de cruzamento com o Rio Canindé, onde o mapa geológico do Projeto RADAM (Nunes

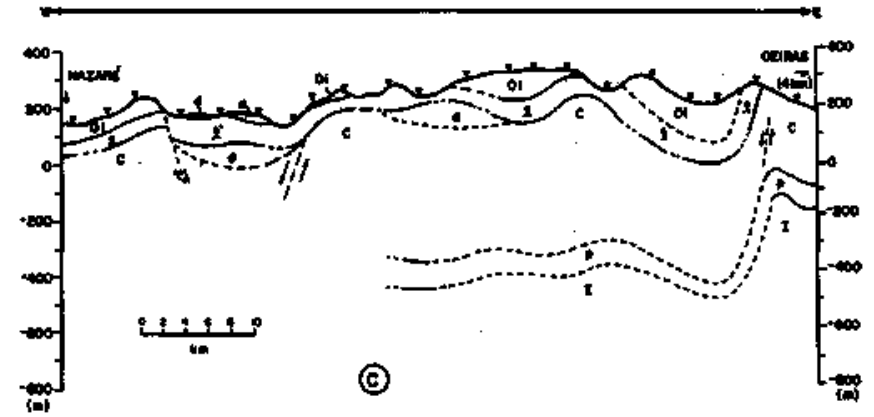

Figura 7 - Perfil geoelétrico C, de Nazaré a Oeiras, Rodovia 230

Figure 7 - Geoelectrical profile C, from Nazaré to Oeiras, Road 230

et al. 1973) indica a ocorrência da Falha do Rio Canindé, de orientação NW-SE e com um rebaixamento entre 200 e 300 m para SW. Outra possibilidade de falhamento ocorre associada à feição com forma de gráben próxima às ocorrências de diabásio, na porção leste do perfil.

Uma camada condutora $t$, em cota de aproximadamente $600 \mathrm{~m}$, inserida em um pacote resistivo, pode corresponder aos sedimentos pelíticos da Formação Tianguá. Uma base resistiva $\mathbf{E}$, a $-1.000 \mathrm{~m}$, abaixo de uma camada condutora a, pode estar relacionada com o embasamento cristalino sobreposto por uma camada sedimentar porosa preenchida por solução salina. Essa profundidade concorda com os soerguimentos inferidos pelas sondagens a partir de Floriano até esse ponto.

PERFIL E O perfil E (Fig 9) inicia-se no perfil D, perto de Dom Expedito, e segue pela Rodovia 316 em direção a Valcnça, em posição paralela à direção das camadas, que mergulham regionalmente para noroeste. A Formação Cabeças aflora em toda a sua extensão, porém as sondagens indicam comportamentos distintos para as regiões ao sul e ao norte de Inhuma. Na parte sul, as sondagens são similares àquelas do perfil $\mathrm{D}$, apresentando um pacote extremamente resistivo, representado pelas seqüências $\mathbf{C}$ e $\mathbf{I}$, entremeadas pela delgada camada condutora $\mathrm{p}$. Ao norte de Inhuma, as sondagens registram um pacote muito menos resistivo, contendo inclusive a camada condutora c. A nível de comparação, a camada $\mathbf{C}$, da porção sul, apresenta resistividades de $56.300 \pm 28.600 \mathrm{ohm} . \mathrm{m}$, enquanto que as camadas Cs e Ci, da parte norte, têm resistividades de $443 \pm 427$

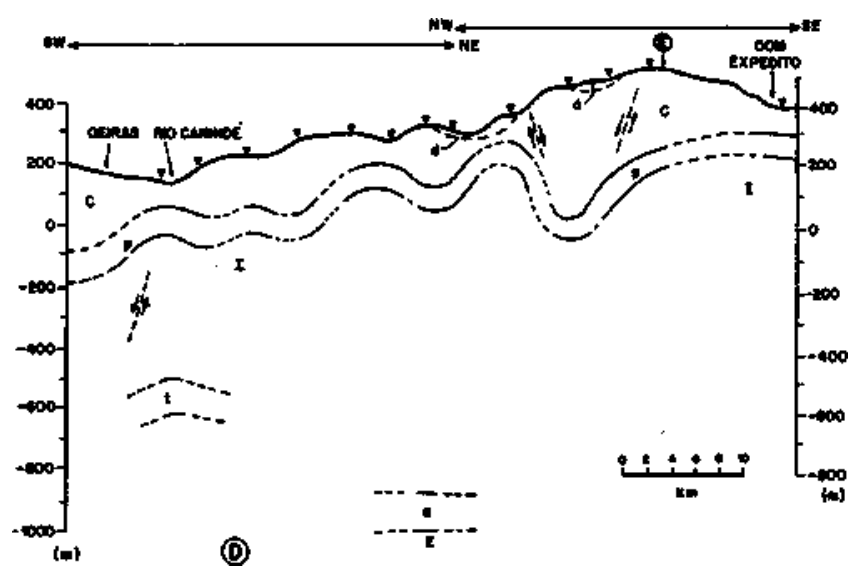

Figura 8 - Perfil geoelétrico D, de Oeiras a Dom Expedito Lopes, Rodovia 230

Figure 8 - Geoelectrical profile D, from Oeiras to Dom Expedito Lopes, Road 230 
e $158 \pm 114$ ohm. m, respectívamente. Pôr falta de maiores informações geológicas, essa variação é aqui interpretada como decorrente de variações faciológicas dos sedimentos da Formação Cabeças. A região ao noite de Inhuma teria sedimentos com componentes mais argilosos do que ao sul, sendo representados por intercalações de folhelhos e siltitos, 0 que favorece a condutividade.

Em termos estruturais, à figura 9 mostra a camada $p$ compondo um amplo sinclinal na região de Ipiranga, anticlinais em Dom Expedito e Inhuma e outro sinclinal ao sul de Valença. Existe a possibilidade de soerguimentos por falhamentos em Inhuma e a NW de Valença.

PERFIL F O perfil F (Fig. 10) é a continuação do perfil D para SE, em direcão a Picos pela Rodovia 230. Nas chapadas, a oeste, afloram os sedimentos da Formação Cabeças, enquanto na planície do Rio Guaribas, que atravessa Picos, a Formação Pimenteiras é encontrada na superfície. Observa-se que a camada $p$ alcança sua posição mais elevada em Dom Expedito e mergulha suavemente em direção a Picos, em situação oposta ao mergulho regional. A base resistiva $\mathbf{E}$, que ocorre ha cota de $-500 \mathrm{~m}$, é interpretada como sendo o embasamento cristalino. Na porção oriental, a camada I apresenta-se fracamente resistiva abaixo da camada p e repousa sobre uma base mais resistiva. Essa sequêencia é interpretada como sendo a Formação Itaim, composta por siliciclásticos finos com maiores teores de argila que aqueles presentes nas unidades do Grupo Serra Grande, sobre as quais se posiciona discordantemente (Cunha 1986). Algumas faixas d, moderadamente condutoras, são interpretadas corno diabásios.

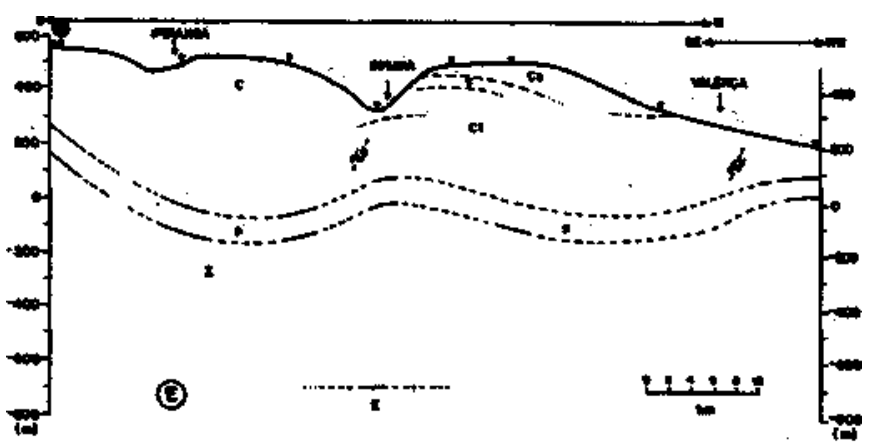

Figura 9 - Perfl geoelttrico E, da Rodovia 230 ald Valença do Piani, ao longo da Rodovia $3 / 6$

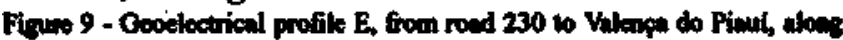
Roed 316

PERFIL G O perfil G (Fig. 11)6 similar ao anterior, pois ilustra a transicão entre as sondagens realizadas nas chapadas, próximas a São José do Piauí, onde afloram os sedimentos da Formação Cabeças, para as da planície do Rio Guaribas. A camada condutora p mergulha de sua posição a $400 \mathrm{~m}$ em São José em direção ao Rio Guaribas, compondo uma feição sinclinal que termina a leste do rio. A camada I é discriminada na porcão NNW do perfil sob a camada p; porém, na porção SSW, a leste de Piços, as sondagens registram uma camada $\mathbf{A}$, muito mais resistiva e interpretada como sendo "Arenitos não-diferenciados". A camada $\mathbf{Q}$, superficial, pode corresponder a sedimentos aluvionares mais recentes, enquanto a base resistiva $\mathbf{E}$, que ocorre na cota de $-400 \mathrm{~m}$, corresponderia ao embasamento.

PERFIL H O perfil H (Fig. 12) corta a planície do Rio Guaribas na região de Bocaina, em direção aproximada NS, até atingir os planaltos a leste de Picos, onde afloram arenitos. Na regiâo norte, observa-se a sequiência $\mathbf{C}, \mathbf{p}$ e I sobre um

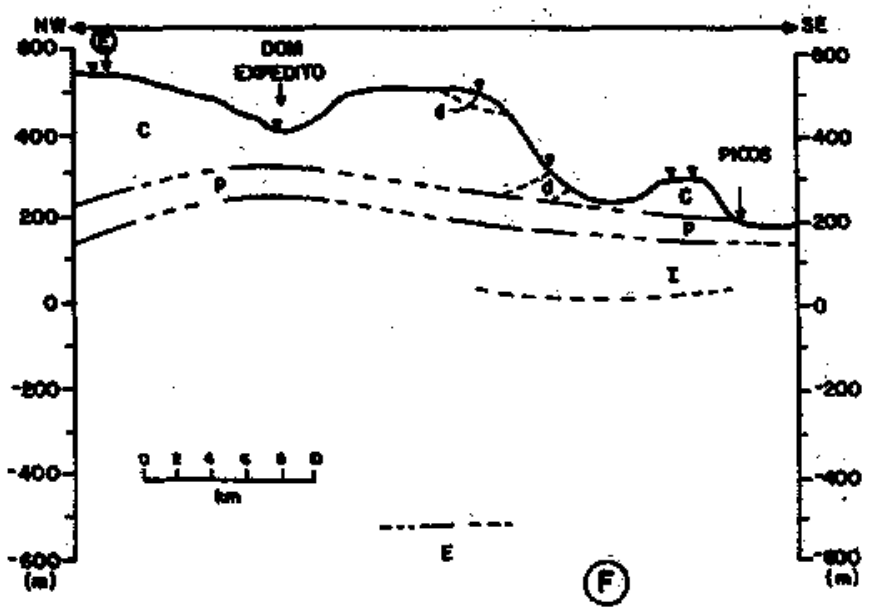

Figura 10 - Perfil geoeletrico F, da Rodovia 316 até Picös, ao longo da rodovia 230

Figure 10 - Geoelectrical profile F, from Roud 316 to Piocos, along rond 230

pacote resistivo. Na parte basal, aparece uma camada a, condutora, sobre uma base resistiva. Nos planaltos, a sudeste, encontramos o pacote resistivo $\mathbf{A}$, que contém uma camada superficial As, e repousa sobre a camada a ou diretamente sobre a base resistiva $\mathbf{E}$. A interpretação sugerida é quê a pane NNW é truncada a leste de Bocaina, provavelmente por uma falha. Essa falha poderia coincidir coin 0 posicionamento e direção do bloco rebaixado da Falha de Picos, onde se encaixa o Rio Guaribas, de acordo com o mapa geológico do Projeto RADAM (Nunes et al 1973). Na porção basal, a camada condutiva a pode ser associada a arenitos saturados por solução salina, posicionados sobre o embasamento cristalino.

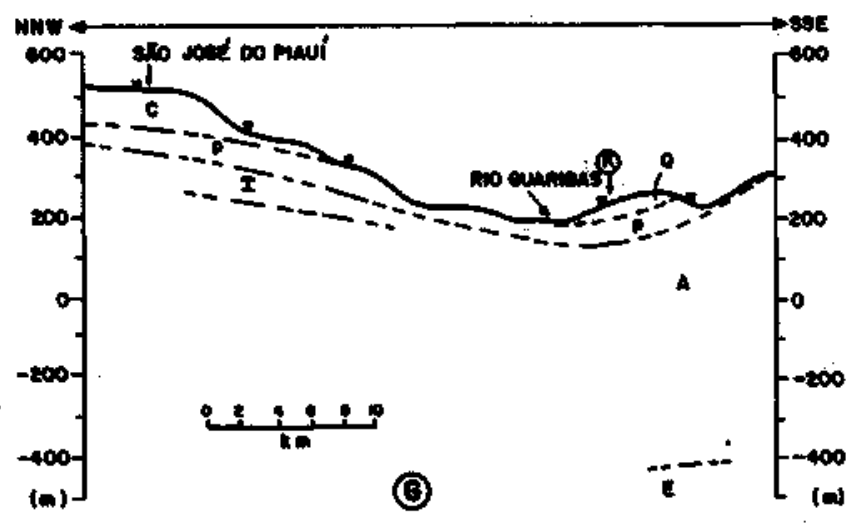

Figura II - Perfil geoeletrico $G$, pela estrada de terra de Seo Jose do Piaul ate o cruzamento com o perfil $K$

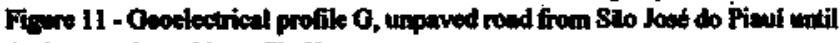
th inerwation with profits $\mathrm{K}$

PERFIL I O perfil I (Fig. 13) localiza-se na Rodovia 020, com direção NE-S W, acompanhando a direção das camadas geoló gicas que, de acordo com a carta geológica de Lima \& Leite (1978), seriam compostas pelos arenitos da Formação Serra Grande diretamente sobre o embasamento cristalino. As sondagens AMT, entretanto, apresentam grande complexidade e heterogeneidade lateral. Em alguns casos, ocorre uma camada As, fracamente resistiva (133 \pm .15 ohm.m), sobre um pacote $\mathbf{A}$, um pouco mais resistivo (630 \pm $230 \mathrm{ohm} . \mathrm{m})$. Camadas condutoras a $(16 \pm 8 \mathrm{ohm}$. m) são 
encontradas em diversas profundidades e, às vezes, sobre a base resistiva $\mathrm{E}$ (resistividades superiores a $2 \times 10^{4} \mathrm{ohm} . \mathrm{m}$ ). A variabilidade lateral pode decorrer de variações faciológicas que alteram a resposta do sinal AMT e/ou movimentação estrutural. Saliente-se que o pacote sedimentar do Serra Grande apresenta variação lateral notável, em decorrência da cimentação caulínica e intercalações de níveis conglomeráticos, de siltitos e folhelhos (Lima \& Leite 1978).

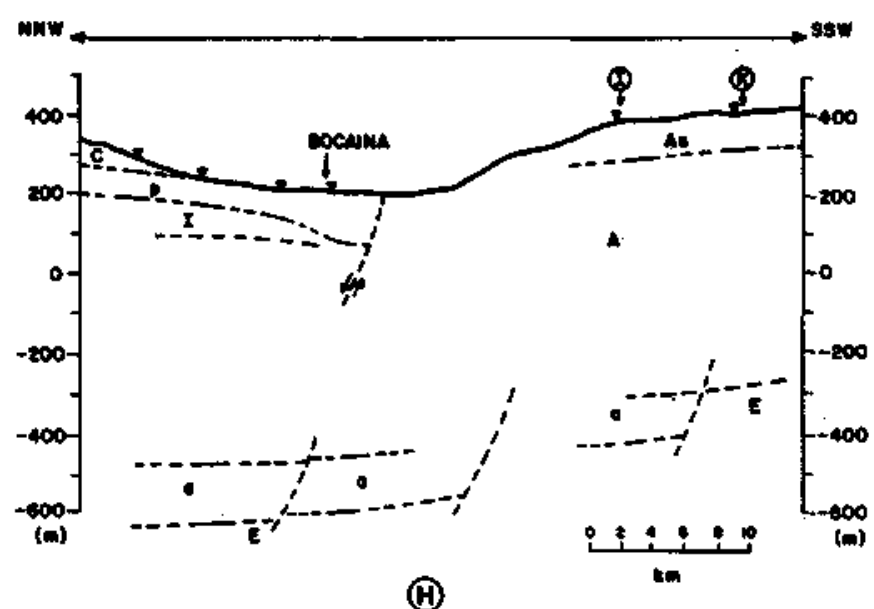

Figura 12 - Perfil geoelétrico $H$, de um ponto a noroeste dê Bocaina, cruzando o perfil I e terminando no perfil $K$

Figure 12 - Geoelectrícal profile $\mathrm{H}$, from a point northwest of Bocaina, crossing over profile I and ending in profile $\mathrm{K}$

Em princípio, um pacote sedimentar composto por arenitos deveria ter uma camada resistiva superficial, não saturada, limitada pelo nível freático, sobreposta a uma camada um pouco mais condutora, composta pelos arenitos saturados. Níveis mais resistivos indicariam menor porosidade, devido à cimentação ou à compactação, e níveis mais condutivos estariam associados a um teor maior de argilas e/ou maior salinidade dos fluidos intersticiais. Nessa região, porém, pode-se observar várias seqüências de camadas. A seqüência mais completa envolve, da superfície para baixo: uma

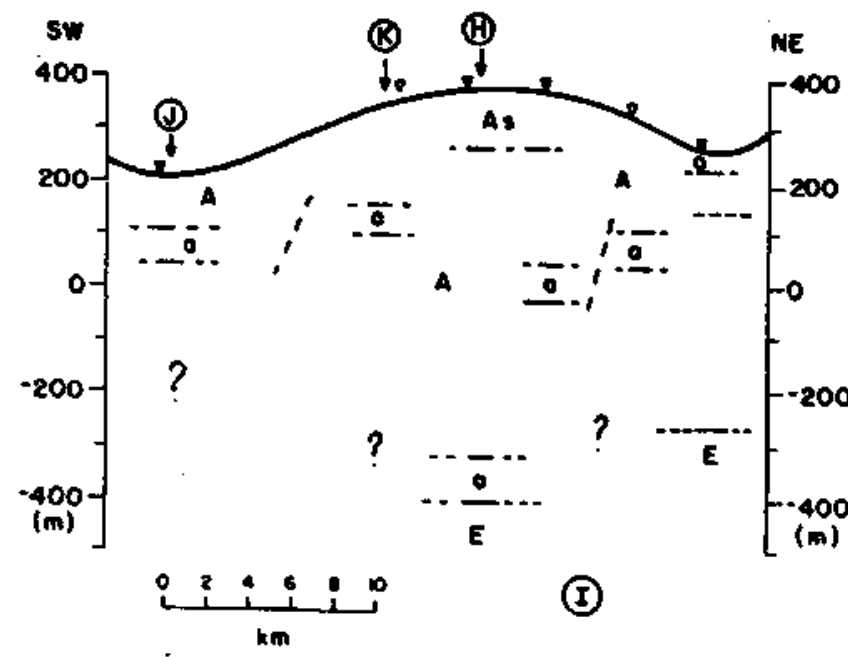

Figura 13 - Perfil geoelétrico I, de um ponto próximo a Francisco Santos, ao longo da rodovia 020, cruzando o perfil $K$, até encontrar o perfil $J$

Figure 13 - Geoelectrícal profile I, from a point near Francisco Santos, along road 020 , crossing profile $\mathrm{K}$, up to profile $\mathrm{J}$ camada superior fracamente resistiva, As, de 30 a $200 \mathrm{ohm}$. m; uma espessa camada resistiva A (superior a $1.000 \mathrm{ohm} . \mathrm{m})$; uma delgada camada condutora a (2 à $10 \mathrm{ohm} . \mathrm{m}$ ) e uma base resistiva $\mathbf{E}$ (acima de $\left.10^{4} \mathrm{ohm} . \mathrm{m}\right)$. A mais simples, por outro lado, envolve uma camada resistiva superficial A que se sobrepõe a uma delgada camada condutora a, que jaz sobre uma base resistiva.

PERFIL J O perfil J (Fig. 14) segue a Rodovia 407, estendendo-se de Picos a Jaicós em direção NW-SE, acompanhando o mergulho das camadas e dando prosseguimento, para SE, aos perfis $\mathrm{F}$ e $\mathrm{G}$.

Em sua porção ocidental, as sondagens revelam que a camada condutora $\mathbf{p}$ ocorre sobre a camada resistiva $\mathbf{A}$ e persiste até $15 \mathrm{~km}$ a leste de Picos. A sudeste desse ponto, onde afloram arenitos, encontramos uma estrutura geoelétrica complexa, similar ao perfil I. A cada sondagem consecutiva em direção SE, o embasamento é encontrado a menores profundidades, evidenciando a aproximação da borda da bacia, situada $10 \mathrm{~km}$ a leste de Jaicós.

Esse perfil cruza tangencialmente a borda sudeste de uma feição circular fotointerpretada, localizada a sudeste de Picos (Nunes et al 1973, Lima \& Leite 1978). As sondagens próximas a essa feição não revelam, porém, nenhuma anomalia geoelétrica.

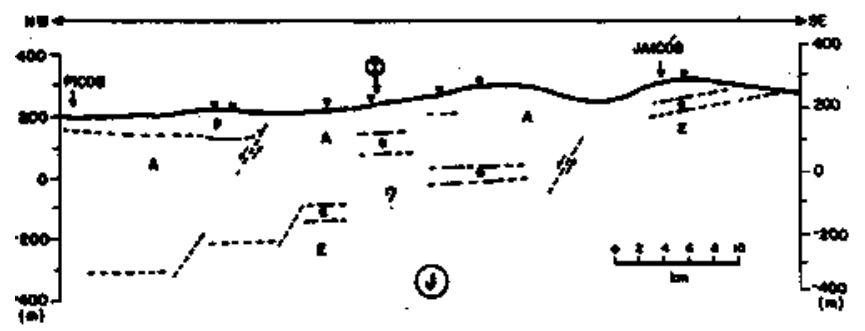

Figura 14 - Perfil geoelétrico J, de Picos até um ponto a sudeste de Jaicós, ao longo da Rodovia 407

Figure 14 - Geoelectrícal profile J, from Picos to a point southeast of Jaicós, along Road 407

PERFIL K O perfil K (Fig. 15) estende-se em direção EW, entre Picos e Alegrete, onde o embasamento aflora. Em condições idênticas ao perfil $\mathrm{J}$, a camada $\mathrm{p}$ é observada até uma distância de $15 \mathrm{~km}$ a leste de Picos, onde é truncada por uma possível falha. Essa região, no entanto, é caracterizada por algumas sondagens que sugerem um possível rebaixamento do embasamento. Pode-se argumentar que isso seria devido à ocorrência de feições com forma de gráben, preenchidas por sedimentos imaturos, em situação similar à que ocorre em Cocpci e São Julião, na borda da bacia a NE e leste dessa região. E importante assinalar que recai sobre essa faixa a projeção do prolongamento do Lineamento Senador Pompeu, que aparentemente condiciona o gráben de Cococi. Uma outra alternativa seria a ocorrência de faixas de paleocarsts em metacalcários ou de outros metassedimentos extremamente fraturados, encontrados sobre rochas mais compactas do embasamento cristalino.

CONCLUSÕES Este trabalho demonstra que, na parte sudeste da Bacia do Parnaíba, os levantamentos AMT conseguem mapear camadas condutoras em profundidades rasas, até $500 \mathrm{~m}$ pelos resultados de inversões unidimensionais. Entretanto, em condições adequadas de alto contraste de condutividade e penetração profunda do sinal, como ocorre em pacotes resistivos, informações podem ser extraídas de profundidades de até $1 \mathrm{~km}$. 


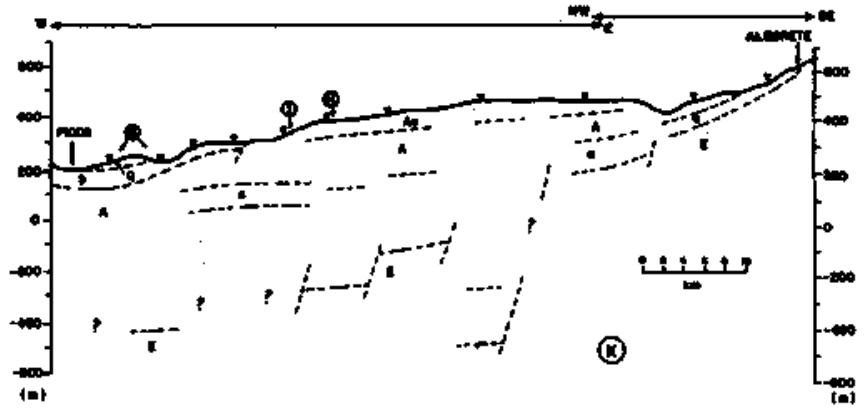

Figura 15 - Perfll geoelétrico $K$, de Picos até Alegnele, ao longo das Rodovias 230 e 316

Figure is - Geoelectrical profile $K$, from Picos to Alegrete, along Roudh 230 and 316

As interpretações baseadas na modelagem unidimensional não são únicas, porém são as mais próximas do conhecimento geológico/geofísico atual, ainda que escasso.

Na porção ocidental da área em estudo, são tentativamente identificadas, em subsuperfície, as Formações Pedra de Fogo, Pastos Bons, Piauí, Longa, Cabeças e Subunidades da Pó ti. $\mathrm{Na}$ parte central e oriental, são discriminadas camadas provavelmente relacionadas à Formação Pimenteiras e arenitos indiscriminados da Formação Itaim e do Grupo Serra Grande.

Os perfis localizados na parte ocidental e central demonstram que sondagens espaçadas de 1 a $2 \mathrm{~km}$ podem discriminar mergulhos suaves nas camadas e deste modo indicar a presença de sinclinais e anticlinais, como acontece por exemplo na região de Boqueirão, Nazaré, Oeiras e Expedito Lopes. Adicionalmente, dobras e falhas subverticais associadas a feições condutoras podem ser inferidas de sondagens com espaçamento de algumas centenas de metros, como exemplificado nos perfis A e B, a leste de Flpriano (Fig. 5 e 6). Nesses casos, modelamentos bidimensionais e tridimensionais são mais apropriados que simples inversões unidimensionais.

As leituras obtidas com a direção do dipolo elétrico orientada paralelamente ao mergulho da feição condutora mostram-se mais propensas a registrarem feições heterogêneas laterais, na direção do mergulho das camadas. De maneira geral, a porção ocidental apresenta-se menos resistiva e mais adequada aos métodos AMT, pelo menos no que se refere à definição de camadas condutivas até $300 \mathrm{~m}$. As razões que justificam esse fato são: o pacote sedimentar é predominantemente pelítico, o nível freático é encontrado próximo à superfície, o relevo é predominantemente baixo e é uma região de maior precipitação pluviométrica.

A porção oriental apresenta condições distintas da porção ocidental. Ali, a seqüência de arenitos, geralmente espessa, ocupa as chapadas e geralmente sobrepõe-se diretamente ao embasamento cristalino. Devido a isso, forma um conjunto resistivo mais susceptível às interferências ao sinal da energia eletromagnética natural. $\mathrm{O}$ sinal tende a ter maior penetração nesses terrenos resistivos, porém a discriminação de finas camadas condutoras em seu interior fica prejudicada. Em alguns pontos, as sondagens indicam condições condutoras em profundidades maiores que o esperado; a explicação sugerida aponta para a possível ocorrência de feições com forma de gráben preenchidas por sedimentos imaturos pré-silurianos. Este levantamento sugere também que o afina men to e o truncamento das camadas sedimentares na parte leste da bacia foram favorecidos por um processo estrutural de soerguimentos e dobramentos das camadas paleozóicas, com a presença de uma série de falhas normais. Essas falhas teriam provavelmente direção NE-SW, em concordância com as direções dos lineamentos e feições estruturais mais conspícuas do embasamento e da bacia. Esses resultados estão de acordo com as conclusões de Fortes (1992), que aponta um sistema de cisalhamento de direção N57E condicionando falhas, dobras e grábens no flanco leste da bacia.

O sistema AMT escalar utilizado neste estudo tem a vantagem de ser pouco dispendioso, é facilmente operado no campo e a manipulação matemática dos resultados obtidos é simples, em casos unidimensionais. Apesar disso, diversos aperfeiçoamentos necessitam ainda ser introduzidos. Na parte de coleta dos dados, pode-se incluir o monitoramento do campo eletromagnético para auxiliar na identificação, correção ou rejeição de dados com interferências no sinal. Na parte instrumental, o acoplamento de um microcomputador pode facilitar o processamento instantâneo dos dados de sondagem, otimizando as campanhas de campo. A determinação da fase entre as componentes elétrica e magnética e a introdução de determinações tensoriais forneceriam maior confiabilidade aos dados, principalmente em relação à determinação de possíveis variações laterais das propriedades elétricas. Na falta de um sistema tensorial, pode-se realizar determinações escalares em 4 direções, com intervalos de $43^{\circ}$, aproximando-se mais das determinações tensoriais (Adam et al 1982). Em áreas de maior complexidade geológica, diagnosticadas pelas inversões unidimensionais, a interpretação pode ser facilitada por uma maior densificaçâo de sondagens e por dados melhor interpretados, por meio de algoritmos que contemplem condições multidimensionais.

Agradecimentos Este trabalho foi desenvolvido com o auxílio do CNPq (Processo n" 402854/90). Expressamos nossos agradecimentos ao colega Francisco M.B. da Cunha e a dois revisores anônimos pelas valiosas sugestões para o texto final.

\section{REFERÊNCIAS BIBLIOGRÁFICAS}

ADAM, A.; KAIKKONEN, P.; HJELT, S.E.; PAJUNPAA, K.; SZARKA, L; VERO, J.; WALLNER, A. 1982. Magnetotelluric and audiomagnetotelluric measurements in Finland. Tectonophysics, 90(1/2):77-90.

BELTRÃO, J.F.; SILVA, J.B.C.; COSTA, J.C. 1991. Robust polynomial fitting method for regional gravity estimation. Geophysics, $\mathbf{5 6}(1): 80-89$.

BILLINGS, A.J. \& THOMAS, J.H. 1990. The use and limitations of nonseismic geophysics in the Papuan Thrust Belt. In: PNG Petroleum Convention, 1. Port Moresby, 1990. Proceedings... Papua, New Guinea, p. $51-62$.

CLIMANÁLISE. 1991. Boletim de Monitoramento e Análise Climática. São José dos Campos, INPE/CPTEC, 6(4): 19-28.

CLIMANÁLISE. 1992. Boletim de Monitoramento e Análise Climática. São José dos Campos, INPE/CPTEC, 7(4):4-5.

CORDANI, U.G.; NEVES, B.B.B.; FUCK, R.A.; PORTO, R.; THOMAZ, A., Fo; CUNHA, F.M.B. 1984. Estudo Preliminar de Integração do PréCambriano com os Eventos Tectônicos das Bacias Sedimentares Brasileiras. Rio de Janeiro, Petrobrás/Cenpes/Sintep. 70 p. (Ciênc. Técn. Petróleo, Sec. Expl. de Petróleo 15).

CRUZ, W.B. \& PEIXOTO, C. 1972. Estudo Hidrogeológico para o Projeto delrrigaçao Lameiro. Recife, Sudene. 142 p. (Série Hidrogeologia 42).
CUNHA, F.M.B. (coord.). 1979. Carta Geológica da Bacia do Parnaiba, escala 1/250.000 - Folhas Floríano (5B23-Z-B) e Oeiras (5B23-Z-D). Rio de Janeiro, Petrobrás/DNPM.

CUNHA, F.M.B. 1986. Evolução Paleozóica da Bacia do Parnaíba e seu Arcabouço Tectônico. Rio de Janeiro. 107 p. (Dissertação de Mestrado, UFRJ).

FEITOS A, E.C. 1970. Estudo Geofisico da Area do Projeto Lameiro, FlorianoPiaui. Recife, Sudene. 31 p. (Série Hidrogeologia 38).

FORTES, F.P. 1992. Os grábens sigmoidais da Bacia do Parnaíba e a matriz Brasiliana. In: CONOR. BRAS. GEOL, 37. São Paulo, 1992. Boletim Resumos Expandidos... São Paulo, SBG. v. 1, p. 552-554.

GÓES, A.M.O.; SOUZA, J.M.P.; TEIXEIRA, L.B. 1990. Estágio exploratório e perspectivas petrolíferas da Bacia do Parnaíba. Boi Geoc. PETROBRÁS, 4(1):55-64.

HOOVER, D.B.; FRISCHKNECHT, F.C.; TIPPENS, C.L. 1976. Audiomagnetotelluríc sounding as a reconnaissaince exploration technique in Long Valley, California. J Geophys. Res., 81(5):801-809.

JUPP, D.L.B. \& VOZOFF, K. 1975. Stable iterative methods for the inversion of geophysical data. Geophys. J. R. Astr. Soc., 42(3):957-976.

LAKANEN, E. 1986. Scalar audiomagnetotellurics applied to base-metal 
exploration in Finland. Geophysics, 51 (8): 1628-1646.

LIMA, E.A A \& LEITE, J.F. 1978. Projeto Estudo Global dos Recursos Minerais da Bacia Sedimentar do Parnaiba - Integração GeológicaMetalogenética. Recife, DNPM/CPRM. 437 p

NUNES, A.B.; LIMA, R.F.; NEGREIROS, B.C. 1973. Geologia. In: PROJETO RADAMBRASIL. Folha SB-23 Teresina e Parte da Folha SB-24 Jaguaribe; Geologia, Geomorfologia, Solos, Vegetação e Uso Potencial da Terra. Rio de Janeiro, DNPM. (Lev. Rec. Nat 2).

PADILHA, A.L. \& VITORELLO, Í. 1993. Estudo audiomagnetotelúrico na Jazida Santa Maria, Minas do Camaquã (RS). In: CONOR. INTERN. SBGf, 3. Rio de Janeiro, 1993. Proceedings... Rio de Janeiro, SBGf. v. 2, p. 1391-1396.

PADILHA, A.L.; TRIVEDI, N.B.; COSTA, J.M.; VITORELLO, Í.; DUPIS A.; CAVOIT, C. 1989. Audiomagnetotelluric study in northeast region of Paraná Basin, South America. Geophysics. 54(7):824-831.

PADILHA, A.L.; VITORELLO, I; TRIVEDI, N.B.; RIBEIRO, M.J.; GROSS

J.M. 1992. Seasonal variation in apparent resistivity probably associated with drastic rainfall changes in southern Brazil. J. Geomag. Geoelectr., 44 (8) :6 51-660.

PADILHA, A.L.; VITORELLO, Í; TRIVEDI, N.B.; COSTA, J.M.; RIBEIRO, M.J.; GROSS, J.M. 1993. Sondagens audiomagnetotelúricas nas proximidades das Minas de Camaquã (RS). Rev. Bras. Geof., 11(1) 81-99.

STRANGAVAY, D.W. \& KOZIAR, A. 1979. Audio-frequency magnetotelluric sounding - a case history at the Cavendish geophysical test range. Geophysics, 44(8): 1429-1446.

VOZOFF, K. 1990. Magnetotellurics: Principles and practice. Proc. Indian Acad. Sci., 99(4):441-471.

MANUSCRITO A750

Recebido em 16 de dezembro de 1992 Revisão do autor em 16 de agosto de 1993 Revisão aceita em 27 de setembro de 1993 